\title{
QUEEN'S
UNIVERSITY
BELFAST
}

\section{Effects of simulation length and flexible foundation on long-term response extrapolation of a bottom-fixed offshore wind turbine}

Barreto, D., Karimirad, M., \& Ortega, A. (2021). Effects of simulation length and flexible foundation on long-term response extrapolation of a bottom-fixed offshore wind turbine. Journal of Offshore Mechanics and Arctic Engineering . https://doi.org/10.1115/1.4053030

Published in:

Journal of Offshore Mechanics and Arctic Engineering

Document Version:

Peer reviewed version

Queen's University Belfast - Research Portal:

Link to publication record in Queen's University Belfast Research Portal

Publisher rights

Copyright 2021ASME. This manuscript is distributed under a Creative Commons Attribution-NonCommercial-NoDerivs License

(https://creativecommons.org/licenses/by-nc-nd/4.0/), which permits distribution and reproduction for non-commercial purposes, provided the author and source are cited.

\section{General rights}

Copyright for the publications made accessible via the Queen's University Belfast Research Portal is retained by the author(s) and / or other copyright owners and it is a condition of accessing these publications that users recognise and abide by the legal requirements associated with these rights.

Take down policy

The Research Portal is Queen's institutional repository that provides access to Queen's research output. Every effort has been made to ensure that content in the Research Portal does not infringe any person's rights, or applicable UK laws. If you discover content in the Research Portal that you believe breaches copyright or violates any law, please contact openaccess@qub.ac.uk. 


\section{Effects of Simulation Length and Flexible Foundation on Long-Term Response Extrapolation of a Bottom-Fixed Offshore Wind Turbine}

2 Facultad de Ingeniería Mecánica, Universidad Nacional de Ingeniería

3 Av. Túpac Amaru 210, Rímac 15333, Lima, Perú

4 dbarretol@uni.pe

5

\section{Madjid Karimirad}

School of Nature and Built Environment, Queen's University Belfast

David Keir Building, Stranmillis Road, Belfast, BT9 5AG, Northern Ireland, United

Kingdom

madjid.karimirad@qub.ac.uk

ASME Membership 102188414

\section{Arturo Ortega}

Universidad Autónoma del Perú

Panamericana Sur Km 16.3, Manzana 'A', Lote 06, Villa El Salvador, Lima, Perú

aortegam@autonoma.edu.pe

\section{ABSTRACT} the modified environmental contour method is used.

This paper deals with statistical and modeling uncertainty on the estimation of long-term extrapolated extreme responses in a monopile offshore wind turbine. The statistical uncertainty is addressed by studying the effect of simulation length. Modeling uncertainty is explored by evaluating the effects of considering a rigid and flexible foundation. The soil's flexibility is taking into account by considering the improved apparent fixity method. To identify the most relevant environmental conditions,

The analysis focuses on the fore-aft shear force (FASF) and the fore-aft bending moment (FABM) at the mudline. The results show that using a simulation length of 10-min, does not provide sufficient

${ }^{1}$ Corresponding author. 
Journal of Offshore Mechanics and Artic Engineering

29 accuracy. It was found that for the FASF, simulation lengths of at least 30-min are required to achieve an

30 accuracy of about $+/-5 \%$. For the FABM, it was found that both the extrapolations made with 20-min and

$3130-$ min simulations achieved similar levels of accuracy of about 20\%. Meanwhile, the results obtained from

32 10-min simulations reached deviations of about $40 \%$.

Finally, from the comparison made between a rigid and flexible foundation, it was found that the

34 extrapolated responses exhibit maximum deviations up to around $5 \%$ and $10 \%$ for the FASF and the FABM,

35 respectively. Also, for the FABM, it was observed that the consideration of a flexible foundation causes the critical wind speed to shift from $16.5 \mathrm{~m} / \mathrm{s}$ (rigid) to $18 \mathrm{~m} / \mathrm{s}$ (flexible).

\section{INTRODUCTION}

41 Although there are many advantages associated with adopting the use of offshore wind

42 energy, one of the most important is undoubtedly associated with its great potential for

43 reducing environmental emissions, which will be essential to curbing global warming.

There is particular interest in the development of offshore wind farms, as higher

45 capacity factors can be achieved. This is because the resource is stronger and more

46 stable in marine environments. However, the main problem that persists in the industry

47 is the Levelized Cost of Energy (LCOE), which in some cases is still high compared to 48 other conventional technologies [1].

49 In an offshore wind energy project, there are a variety of factors that will affect

50 the LCOE [2], however, the individual capacity of the turbine draws special attention.

51 Manufacturers are continually pushing established power capacities to new levels [3] as

52 larger turbines provide increased capacity per foundation. Similarly, a major component 
Journal of Offshore Mechanics and Artic Engineering

53 in the investment cost is the foundation which can represent up to $25 \%$ of the total

54 project investment cost [4].

55 Considering these two points, it is expected that a significant reduction in the

56 LCOE can be achieved by using very large turbines with the most economical foundation

57 available that fully satisfies the reliability requirements of the project. For offshore, fixed

58 foundations have been preferred by most of the projects installed in the world,

59 especially the monopile as it has the lowest relative cost [5]. Given the popularity of this

60 type of foundation, there is still interest in optimizing it to reduce costs without

61 sacrificing reliability.

This cost reduction can be achieved through a more detailed understanding of

63 the key uncertainties present in the initial phase of the project that may lead to changes

64 in the current design processes. These key uncertainties are associated with direct

65 impacts on turbine loads (i.e. extreme events, aero-hydro-servo-elastic response, soil-

66 structure interaction, and load extrapolation) [6]. Controlling the level of uncertainty in

67 the probabilistic models is expected to produce good and robust predictions of the

68 extrapolated loads/responses associated with target return periods [7], and thus obtain

69 an optimized product with reduced LCOE.

70 The present research addresses the statistical and modeling uncertainty. For the

71 first type of uncertainty, the study is centered on exploring the errors incurred when

72 length simulations shorter than one hour are used for the 50-yr long-term response

73 extrapolation. Simulation lengths of 10,20 , and 30 minutes are evaluated and compared

74 against the 1-hr and 50-yr extreme values. Thus, it is intended to cover certain aspects 
Journal of Offshore Mechanics and Artic Engineering

75 not taken into account in the current state of the art and provide relevant conclusions

76 to guide future efforts in this area, in which there is still no consensus.

77 The second type of uncertainty is assessed by taking into account the flexibility

78 of the foundation to evaluate its influence on the long-term responses of a bottom-fixed

79 offshore wind turbine (OWT). The improved apparent fixity model is considered and the

80 results from 1-hr coupled simulations are compared against the results obtained with a

81 fully rigid foundation model. This is done to identify the divergences generated in the

82 extreme long-term responses, particularly concerning the identification of the critical

83 environmental condition. This is a very important aspect that has not received sufficient

84 attention in the current literature.

85 This document is structured as follows. First, a brief description of the 86 uncertainty related to wind energy is presented. Then, the theory behind the

87 environmental contour method is introduced, covering the traditional (ECM) as well as

88 the modified (MECM) version. Later, the statistical extrapolation procedure based on

89 the Global Maxima Method is presented. In the following section, the details of the 90 numerical model are explained. Then, the results obtained are presented and discussed.

91 In the last section, the conclusions and suggested aspects for future research are 92 summarized.

93

94 UNCERTAINTY IN WIND ENERGY

95

96

Uncertainties are present in any natural random process. It is difficult to make

97 appropriate decisions without considering them in the design process. Many parameters 
Journal of Offshore Mechanics and Artic Engineering

98 for structural design are rarely known with great confidence and, they should be taken

99 as random variables when considering a stochastic approach. In general, at least three

100 types of uncertainty can be recognized in structural reliability theory [8]:

101 - Physical uncertainty, related to physical quantities and measurements such as

$102 \quad$ loads and material properties.

103 - Statistical uncertainty, related to deviations arising from the estimation of

104 parameters of probability distributions caused by insufficient sample size or $105 \quad$ insufficient observations.

106 - Model uncertainty, related to simplifications, assumptions, other effects (e.g. non-

107 linearities), and interactions with other variables not initially considered in the 108 physical or mathematical models.

109 A comprehensive understanding of the nature of uncertainties and how to 110 quantify them is crucial to optimize the design phase of offshore wind structures. This

111 aspect has been highlighted in the conclusions of the literature review performed by

112 Jiang et al. [9]. The ultimate goal is to estimate loads as accurately as possible with

113 appropriate levels of reliability but minimizing computational effort. The following two

114 subsections will explore how two specific types of uncertainty arise in the offshore wind

115 industry. The first one, related to the simulation length, and the second one, associated

116 with the foundation flexibility.

117 a) STATISTICAL UNCERTAINTY

119 The offshore wind energy industry can be considered to be still at an early stage 120 of development. For this reason, real data is not often available, or at least not in the 
Journal of Offshore Mechanics and Artic Engineering

121 required volume. As a consequence, it is necessary to rely on computational models that

122 accurately represent real-world physical phenomena. Similarly, since extreme events

123 have a very small probability of occurrence, it is necessary to perform several stochastic

124 realizations to reach an acceptable level of accuracy on the statistical parameters. This

125 involves time-consuming activities and the use of very large computational resources,

126 which can make this a prohibitive process.

127 To alleviate this problem, it is often necessary to perform shorter simulations

128 that can be later extrapolated and, thus, obtain answers about long-term processes.

129 However, this consideration will introduce statistical uncertainty into the results.

130 Therefore, the simulation length needed to achieve an acceptable accuracy of an

131 extrapolated load is a crucial aspect. Choosing a very short time may greatly decrease

132 the computational effort, but will cause the results to have a significant error level in the

133 statistical estimates. Conversely, longer simulations may require more calculation time,

134 but the result will be closer to the true values of the stochastic process parameters.

135 In the wind industry, a simulation length of ten minutes has been considered

136 enough to ensure statistical independence and stationarity [7], and it is currently the

137 standard applied in the industry [10]-[13] for OWTs. However, this assumption is

138 already being considered conservative for the offshore environment [10]. Similarly, it is

139 common practice in the offshore industry to consider simulation lengths between 3 to 6

140 hours for floating structures [14]. However, if the combined wind and wave loading is

141 considered, the assumption of stochastic independence for periods longer than one

142 hour cannot be considered entirely true, especially for the wind spectrum. This 
Journal of Offshore Mechanics and Artic Engineering

143 discrepancy has been highlighted by Kvittem et al. [15]. Then, it is expected that

144 simulations of more than ten minutes will be required to reduce the uncertainty in the

145 extrapolation of dynamic responses of OWTs. Although there is research focused on

146 obtaining clear conclusions on this subject, unfortunately, there is still no clear

147 consensus.

148 The first effort found in the literature addressing the simulation length problem

149 was made by Haid et al. [16]. They analyzed simulation lengths between ten minutes to

150 six hours on an OWT supported by a spar-type structure (OC3 Hywind). This study

151 assessed ultimate loads but only in the short term, without applying any type of

152 extrapolation. No technique was applied to obtain some kind of statistical distribution of

153 the extreme values, instead, maximum single values extracted from time series were

154 averaged and then compared. The main conclusion of the study was that a simulation

155 length longer than ten minutes makes little difference to the ultimate loads.

156 Following the line of the previous study, Zwick et al. [17] also focused on the

157 simulation length problem, but this time applied to a bottom-fixed OWT (OC4 Jacket). In

158 this work, the extrapolation of loads to 50 years is considered, and the peak-over-

159 threshold method adjusted to an exponential function is used. The paper concludes that

160 using different simulation lengths has an appreciable impact on ultimate loads.

161 More recently, Hübler et al. [18] focused their efforts on studying the effects of

162 simulation length on a monopile and a jacket OWT. The analysis was centered on short-

163 term loads, so no extrapolation technique was applied. Furthermore, they did not use

164 any method to statistically characterize the distribution of the extreme values, so the 


\section{Journal of Offshore Mechanics and Artic Engineering}

165 results were based on singular maximum values extracted from simulations. The

166 conclusions of this work indicate that the simulation length is not relevant.

167 Finally, Pillai et al. [19] studied the impact of simulation length on a semi-

168 submersible OWT. In this work, no joint distribution of environmental parameters was

169 considered, and only a limited number of wind speeds were evaluated. The results were

170 based on a comparison of the maximum values of the time series, so no characterization

171 of the statistical distribution of the extreme values was made, nor any extrapolation

172 technique was applied. The authors concluded that simulations longer than ten minutes

173 are required to correctly capture the behavior of the system, in contrast to the results

174 found by Haid et al. [16].

175 Two things can be concluded from the previous paragraphs: there are

176 discrepancies among the conclusions of the studies and, there are aspects that have not

177 been taken into account in the current state of the art. The studies have been mainly

178 focused on extreme short-term loads, and only one of them has considered the

179 extrapolation of long-term loads. Also, the analyses have not contemplated fitting the

180 extreme values to a statistical distribution (e.g. Gumbel), this is because in some cases,

181 few stochastic realizations have been considered for the environmental conditions

182 analyzed, and in other cases, the averaging technique have been preferred by the

183 authors. Later, it will be seen that in this work it has been possible to cover these

184 pending aspects thanks to the use of the MECM, which has allowed focusing the

185 computational effort on a specific set of environmental conditions.

186 b) MODELING UNCERTAINTY

187 
Journal of Offshore Mechanics and Artic Engineering

This uncertainty is related to the soil-structure interaction. For bottom-fixed

189 OWTs, this aspect is particularly relevant as there are large and direct connections

190 between the substructure and the seabed. The work required to avoid this type of

191 uncertainty is not easy. It is necessary to use more complete models that replicate the

192 physical phenomena with sufficient precision. Particularly, in this paper, we are

193 interested in the long-term extreme responses. Surprisingly, within the literature it is

194 rare to find studies that address the effect of the soil on extreme dynamic responses,

195 being the effects of the foundation model on the fatigue loads or the prediction of the

196 natural frequencies of the system the most addressed topics.

197 An early work that addressed the issue of extreme responses was performed by

198 Bush et al.[20]. In that research, a comparison of a rigid foundation versus a flexible

199 foundation based on the apparent fixity (AF) method was performed in a monopile

200 OWT. In this case, only one wind speed was analyzed and only the fore-aft bending

201 moment at the mudline was considered. Subsequently, this research was extended [21]

202 to include the coupled springs (CS) and the distributed springs (DS) foundation models.

203 Again, only the fore-aft bending moment at the mudline was analyzed for two wind

204 speeds. They concluded that the rigid model underestimates the extreme responses.

205 However, it is important to note that this study was quite limited, and although 150

206 stochastic realizations were performed for each wind speed, the results were mainly

207 based on statistical measures calculated from the samples. They did not fit an extreme

208 value probability distribution to the data obtained from the simulations to find the most

209 probable extreme response. 
Journal of Offshore Mechanics and Artic Engineering

211 i.e. fully rigid, $\mathrm{AF}, \mathrm{CS}$, and DS; the last two are the most complex, but they are expected

212 to replicate the soil flexibility more accurately. However, using very complex models can

213 increase the computational effort required to complete the simulations. Thus, the same

214 problem that was observed with statistical uncertainty arises again. Therefore, it is

215 necessary to use a model that allows finding a trade-off between computational cost

216 and accuracy to reflect the soil-structure interaction. In this way, the most influential

217 aspects can be identified to delimit the domain of the different environmental variables,

218 which will deserve to be analyzed using more complex models at a later stage.

219 The simplest model to take into account the soil-structure interaction is the AF

220 model. Unfortunately, there are some problems with this method, since it is common

221 that only the diagonal terms of the stiffness matrix of the fictive beam are matched, and

222 the cross-coupling stiffness between the horizontal and rotational degree of freedoms

223 are neglected. Løken et al. [12] managed to solve this problem by considering a second

224 fictitious beam with different properties. This method is known as the Improved 225 Apparent Fixity (IAF) Method. The advantage of this model is that it is still simple as AF, 226 and can be properly implemented SubDyn module of FAST. The IAF provides a better 227 replication of the foundation conditions than a rigid model, but at the same time does 228 not increase the computational complexity dramatically. This is the model employed in 229 the present study.

230 ENVIRONMENTAL CONTOUR METHOD: TRADITIONAL AND MODIFIED 
Journal of Offshore Mechanics and Artic Engineering

Haver et al. [22] proposed the ECM as a practical approach for estimating long-

233 term extreme responses by using short-term analysis. In general terms, the method can

234 be summarized in Eq. 1 . In this expression, it is assumed that the short-term period is

235 one hour. $\mathbf{F}$ is the cumulative distribution function of the extreme value $(\xi)$ of the

236 analyzed response $\mathrm{X}$. Hereafter, $\mathbf{U}_{\mathrm{w}}$ represents the mean wind speed at the hub height,

237 while $\mathbf{u}, \mathbf{h}$, and $\mathbf{t}$ represent the mean wind speed measured at $10 \mathrm{~m}$ above the still water

238 level, the wave height, and the wave peak period, respectively. The set $\left\{u_{N}, h_{N}, t_{N}\right\}$

239 represents the most relevant environmental condition for a given return period $\mathbf{N}$.

$$
\mathrm{F}_{\mathrm{X}_{1 \mathrm{hr}, \mathrm{N} \text { yr }}}(\xi) \approx \mathrm{F}_{\mathrm{X}_{1 h r} \mathrm{U}_{\mathrm{W}, \mathrm{H}_{\mathrm{S}}, \mathrm{T}_{\mathrm{P}}}}\left(\xi \mid \mathrm{u}_{\mathrm{N}}, \mathrm{h}_{\mathrm{N}}, \mathrm{t}_{\mathrm{N}}\right)
$$

To apply the traditional ECM, it is needed to define the reliability index $\beta_{s}$, Eq. 2.

241 Here, $\boldsymbol{\Phi}$ represents the standard normal cumulative probability function, and $\mathbf{m d}$ is the

242 expected number of $d$-hour sea states per year. The environmental conditions

243 associated with a specific return period can be found by using the Rosenblatt 244 transformation [23].

$$
\beta_{\mathrm{s}}=\Phi^{-1}\left(1-\frac{1}{\mathrm{~N} * \mathrm{md}}\right)
$$

245 Once the environmental conditions to be evaluated have been identified, the

246 corresponding dynamic responses are determined. For a given environmental condition,

247 short-term extreme values of the response are used to fit an empirical probability

248 distribution to find the most probable extreme value. The combination which gives the

249 maximum extreme response, among all the sets, is known as the "design point" and, the

250 response value for this condition is considered the long-term extreme response $(\mathrm{N}-\mathrm{yr}$ 
Journal of Offshore Mechanics and Artic Engineering

251 response). However, since the ECM omits the response variability at the beginning, it is

252 necessary to correct the calculated extreme value. This correction is made by applying 253 an empirical fractile level higher than $50 \%$. Values between $70 \%$ and $90 \%$ are usual for 254 practical applications [24].

255 Although the traditional ECM is a widely used method in the offshore industry, it 256 does not give accurate responses for systems that have survival mechanisms based on 257 an active control system. This aspect causes the ECM to underestimate the long-term 258 extreme responses, which are mainly influenced by environmental conditions within the 259 operational range and with a higher probability of occurrence.

260 To bypass that problem, Li et al. [25] proposed the MECM. It is based on the 261 widely accepted assumption that the long-term probability distribution of a response 262 can be extrapolated from the short-term distribution as short-term extreme values are 263 considered statistically independent in a short-term period e. g. one hour. Then, the 50-

264 yr 1-hr extreme cumulative distribution function (CDF) can be written as Eq. 3. This 265 equation implies that the 50-yr extreme response can be found by estimating an 266 extreme response with a lower return period $N_{0}$. This procedure helps to bypass the 267 non-linearity on the limits of the operational range of the wind turbine. Since the return 268 period $\left(\mathrm{N}_{0}\right)$ will be lower than 50 years, it is necessary to apply an extrapolation to the 269 probability distribution between brackets to estimate the corresponding value of the 270 response at 50 years. This extrapolation is achieved by applying the exponent $50 / \mathrm{N}_{0}$. 271 The expression between brackets can be found by applying the traditional ECM, Eq. 1, 
Journal of Offshore Mechanics and Artic Engineering

272 then it becomes Eq. 4 but, considering the return period $N_{0}$. In this case, the extreme

273 response is calculated using one-hour short-term extreme distribution.

$$
\begin{aligned}
& \mathrm{F}_{\mathrm{X}_{1 \mathrm{hr}, 50 \mathrm{yr}}}(\xi)=\left[\mathrm{F}_{\mathrm{X}_{1 \mathrm{hr}, \mathrm{N}_{0} \mathrm{yr}}}\right]^{50 / \mathrm{N}_{0}}
\end{aligned}
$$

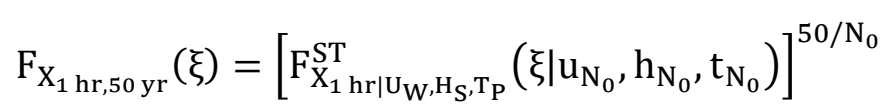

Consequently, the MECM focuses on finding the return period $N_{0}$ in which the

275 maximum long-term extreme response is achieved. To reach this goal, many inner

276 environmental contours corresponding to wind speeds within the operational range of

277 the turbine need to be tested. The condition that provides the greatest response

278 among all the conditions tested will be the most important environmental condition or,

279 it can be also referred as the critical environmental condition. The return period that

280 corresponds to this important condition will be the return period required, $\mathrm{N}_{0}$. A specific

281 procedure to apply the MECM to bottom-fixed OWTs under the combined action of

282 wind and wave can be found in [25].

283 LOAD EXTRAPOLATION

284

In this research, the Global Maxima Method is used to obtain a short-term

286 probability distribution. The extreme values obtained from coupled simulations are

287 fitted to a Gumbel distribution, Eq. 5. In this expression, $X$ is the analyzed response, $\beta_{G}$ is

288 the shape parameter, and $\mu_{\mathrm{G}}$ is the location parameter and, at the same time, the most

289 probable value of the probability distribution (Mox), also known as the mode.

$$
F(X)=\exp \left(-\exp \left(-\frac{\left(X-\mu_{G}\right)}{\beta_{G}}\right)\right)
$$


Journal of Offshore Mechanics and Artic Engineering

As previously stated, it is necessary to have the 1-hr extreme probability

291 distribution for the extrapolation of 50-yr extreme responses using the MECM. This can

292 be achieved by running one-hour simulations or by using shorter simulations and then

293 applying an extrapolation to arrive at a one-hour level. For this purpose, extreme values

294 extracted from 10-min, 20-min, 30-min, and one-hour simulations are used to compare

295 the deviations in the most probable values of the fitted Gumbel distributions. After

296 extrapolation, the most probable value of the Gumbel distribution is given by Eq. 6. In

297 this equation, $N_{0}$ is the return period of the environmental condition (EC) tested. The

298 parameter $\mathbf{r}$ will depend on the simulation length from which we have extracted the

299 extremes for fitting purposes. The value of $r$ is $1,2,3$, or 6 if the extremes for the

300 Gumbel fitting come from 1-hr, 30-min, 20-min or 10-min simulations, respectively.

$$
\mathrm{Mo}_{\mathrm{X}}=\mu_{\mathrm{G}}+\beta_{\mathrm{G}} \cdot \ln \left(\mathrm{r} \cdot 50 / \mathrm{N}_{0}\right)
$$

In the original paper where the MECM was developed [25], as well as in further

303 the empirical distribution. This approach is based on the least-squares method;

304 however, some limitations have been identified when it is used for extreme value fitting

305 [26]. For this reason, the maximum likelihood method is employed in this work.

306 Considering that 2 dynamic responses, 12 environmental conditions, 2 different

307 foundation models, and 4 simulation lengths were analyzed, a total of 120 parameter

308 estimates were made. The goodness of fit is determined by the $p$-value obtained after

309 performing a hypothesis test based on Moran's statistic, which is implemented in WAFO

310 [27]. The criterion for accepting the parameter fit is that the calculated $p$-value is 
Journal of Offshore Mechanics and Artic Engineering

311 greater than 0.05 (significance level). The higher the $p$-value, the better the goodness of

312 fit. Table 1 presents the number of parameter estimation cases grouped by the range of

313 the p-value obtained. It is observed that in 102 cases, out of a total of 120 , the p-values

314 are higher than 0.10 .

315 NUMERICAL MODEL

For the development of this research, the NREL $5 \mathrm{MW}$ wind turbine model [28]

318 supported on a monopile foundation is considered. This wind turbine is a variable speed

319 and collective pitch wind turbine with rated, cut-in, and cut-out wind speeds of $11.4,3$,

320 and $25 \mathrm{~m} / \mathrm{s}$, respectively. The hub is $90 \mathrm{~m}$ above the mean sea level and, it has a rotor

321 and hub diameter of $126 \mathrm{~m}$ and $3 \mathrm{~m}$, respectively.

322 The offshore reference site used in this study is the one labeled as "Site 15"

323 presented by Li et al. [29], which is located in the North Sea center. The joint probability

324 distribution considers three environmental parameters. The coefficients of the statistical

325 distributions can be found in the referred work [29]. Under the MECM procedure,

326 different environmental conditions are obtained; these conditions are listed in Table 2.

327 In the first part of the work, it is necessary to generate the inflow wind profiles

328 for each wind speed to be evaluated, and considering several random seeds, this is done

329 with the help of TurbSim [30]. The Kaimal turbulence spectral model is used, with a

330 characteristic and turbulence type of "B" and "NTM", respectively. The wind power-law

331 is used to extrapolate wind speeds along the tower and rotor height. For the generation

332 of the stochastic wind field, it is considered the coherence model given by IEC 61400-1

333 (3rd ed.) [31] and, a time step of $0.05 \mathrm{~s}$. 
Journal of Offshore Mechanics and Artic Engineering

For each wind speed, there will be an associated sea state and then, it is

335 necessary to set the values for the wave height (Hs), peak spectral period (Tp), and the

336 cut-off frequencies of the wave spectrum in the input files of FAST [32]. Wave profiles

337 are generated internally with HydroDyn [33] and using the JONSWAP spectrum with a

338 peak-shape parameter of 3.3 . The heading wave direction is set to $0^{\circ}$ and the water

339 depth is $20 \mathrm{~m}$. The analysis time considered for incident wave calculations is $3630 \mathrm{~s}$.

340 Additionally, one hundred simulations have been performed with different random

341 seeds for each environmental condition tested.

342 The monopile that supports the turbine has a diameter of $6 \mathrm{~m}$ and a thickness of

$3430.06 \mathrm{~m}$, and it is considered fully constrained at the seabed for the first part of this work.

344 An important part of achieving accurate dynamic responses when considering wave

345 loading is to properly set the Morison coefficients for drag $\left(C_{D}\right)$, added mass $\left(C_{A}\right)$, and

346 pressure $\left(C_{P}\right)$. The usual ranges for these values are: $1.5 \leq C_{P}+C_{A} \leq 2$ and, $0.6 \leq C_{D} \leq 1.2$,

347 according to [34]. For this work, the coefficients have been taken as $C_{D}=0.9, C_{A}=0.75$,

$348 C_{P}=1$, for a detailed explanation about the selection of these values the reader is

349 referred to [35] which is also supported by [36]. Other input parameters have been left

350 as they were defined in the NREL $5 \mathrm{MW}$ baseline. For the part of the analysis regarding

351 the inclusion of the soil flexibility, the IAF method has been taken into account, more

352 details of this model can be found in [12]. A scheme of these two fictitious beams with

353 three nodes can be seen in Fig. 1. Here, the lowest node $\left(N_{1}\right)$ has a fully rigid condition.

354 A summary of their main properties is summarized in Table 3. Finally, all these models 
Journal of Offshore Mechanics and Artic Engineering

355 and, workflows are implemented in a Python script to generate the output files from

356 FAST. The post-processing for Gumbel fitting is made with WAFO [27].

357 RESULTS

358

359 The results of the analysis for the fore-aft shear force (FASF) and fore-aft

360 bending moment (FABM) at the mudline are presented below. First, the effect of the

361 simulation length on the extrapolation will be analyzed, both for the extrapolated loads

362 at a level of 1-hr and 50-yr. In the case of 1-hr extrapolation, there is no effect of the

363 return period of each wind speed, factor $50 / \mathrm{N}_{0}$, in the extrapolated load, Eq. 6. But, for

364 the 50-yr extrapolation, this factor does have an influence. A rigid soil model is

365 considered in all cases.

366 In a later section, the results obtained from the comparison between the

367 responses using the rigid soil model and the IAF soil model are discussed. In this case, 1-

$368 \mathrm{hr}$ simulations are used. In each case, both the trends of the values and the relative

369 errors are shown. In both sections of the results, the relative error is plotted. For the

370 case of simulation length analysis, the relative error is calculated according to Eq. 7, and

371 for the case of the study of the effect of soil flexibility, the relative error is given by Eq.

3728.

$$
\begin{gathered}
\text { R. E. }=\left(\frac{X_{i-\min }-X_{1 h r}}{X_{1 h r}}\right) \times 100 \% ; i=\{10,20,30\} \\
\text { R. E. }=\left(\frac{X_{\text {IAF }}-X_{\text {Rigid }}}{X_{\text {Rigid }}}\right) \times 100 \%
\end{gathered}
$$

373 a) Effects of simulation length 
Journal of Offshore Mechanics and Artic Engineering

First, the trend of the most probable values extrapolated from extreme values

376 obtained from $10-\mathrm{min}, 20-\mathrm{min}$, and $30-\mathrm{min}$ simulations will be analyzed. All these values

377 have been extrapolated to the level of 1-hr. The trend for the FASF is shown in Fig. 2; it

378 can be also observed the most probable value obtained from one-hour simulations

379 fitting. As can be seen, the difference between the extrapolated most probable values is

380 small in comparison to the trend obtained with the one-hour simulations (black line

381 with diamonds). In the case of the FABM, Fig. 3, a slightly greater variation is observed.

382 In this case, the extrapolation obtained from 30-min simulations is the one that best

383 agrees with the one-hour simulations trend.

384 Figures 4 and 5 show the relative errors obtained for the FASF and FASBM 385 respectively. In these figures, the most probable values of the extremes obtained from 386 10-min, 20-min, and 30-min simulations extrapolated to a 1-hr level are compared to 387 the most probable value obtained from 1-hr simulations. In the case of the FASF, the 388 relative error varies between $-2 \%$ and $6 \%$ whereas this variation ranges from $-6 \%$ to $+6 \%$ 389 for the FABM depending on the wind speed considered. In both cases, it is observed 390 that the 30-min simulation offers lower levels of relative error.

391 From Figs. 2-5, it can be seen that when extreme values characteristics obtained 392 with shorter simulations are extrapolated to the one-hour level, there is no large 393 difference with simulations that have been run for one full hour. Now it will be explored 394 what happens when the extrapolation is done at a level of 50 years. In this case, the 395 factor $50 / \mathrm{N}_{0}$ will influence the most probable extrapolated value of the extreme 396 response since it is different for each wind value. As it can be noticed in Fig. 6, the 
Journal of Offshore Mechanics and Artic Engineering

397 divergence for FASF becomes greater; being the extrapolation obtained from the 30

398 minutes simulations the one that comes closest to the value obtained from 1-hr

399 simulations. In the case of the FABM, Fig. 7, all extrapolations show a significant

400 deviation from the 1 -hr case, but the extrapolation obtained from 10 -min has the

401 largest difference. It can also be seen that both the 20-min and 30-min extrapolations

402 perform almost the same. Also, it is observed that the critical environmental condition

403 for 10 minutes simulations moves from $16.5 \mathrm{~m} / \mathrm{s}$ to $17 \mathrm{~m} / \mathrm{s}$ for the case of 20 -min and

404 30-min simulations.

$405 \quad$ These differences are better understood when the relative errors are plotted. In

406 the case of the FASF, Fig. 8, the relative error is higher for the 10-min and 20-min cases,

407 and the error for the extrapolation obtained from the 30-min varies in the range of +-

$4085 \%$. In the case of the FABM (Fig. 9), it is observed that both 20-min and 30-min perform

409 similarly, but using 10-min gives the highest relative error. In the 20-min and 30-min

410 cases, the error varies between $+20 \%$ (for critical wind speed) and $-10 \%$ (for higher

411 speeds and near the cut-out wind speed).

\section{2 b) Effects of flexible soil}

413

414 In this section, the effects of considering the soil flexibility through the IAF soil

415 model on load extrapolation will be explored. For this analysis, 1-hr simulations are used

416 and extrapolation is applied to reach 50-yr levels. In Figs. 10 and 11, the trend of the

417 most probable values of the extreme responses in 1-hr can be observed for FASF and

418 FSBM, respectively. As it can be noticed, the difference between both curves is small.

419 Similarly, in Fig. 12 the relative errors for the FASF and the FABM are observed. In this 
Journal of Offshore Mechanics and Artic Engineering

420 case, the comparisons are made between the response obtained considering the IAF

421 and the response obtained with the rigid foundation. So, an increase of up to about $3 \%$

422 for the FASF and about $2 \%$ for the FABM is observed when considering soil flexibility.

423 In Fig. 13, it can be seen that there is no great variation in the values of FASF

424 when the extrapolation to a $50-y r$ level is applied. In contrast, the FABM experiences

425 some variations, Fig.14. The critical environmental condition moves slightly from the

$42616.5 \mathrm{~m} / \mathrm{s}$ speed to $18 \mathrm{~m} / \mathrm{s}$. Also, the most likely value after extrapolation increases. This

427 behavior can be seen more clearly in Fig. 15. The FASF has maximum deviations close to

$4284 \%$, and the FABM reaches up to $10 \%$ for $18 \mathrm{~m} / \mathrm{s}$ where the critical mean wind speed is

429 found.

430 CONCLUSIONS

431

One of the main concerns for the development of offshore wind energy is the

433 reduction of the LCOE. It has been identified that one of the ways to achieve this is to

434 control the level of uncertainty present in the initial phase of the projects that could

435 lead to changes in the current design processes and thus help to avoid over-

436 conservative designs with excessive material. This would produce good and robust

437 predictions of the short- and long-term dynamic responses associated with specific

438 return periods. However, this is not an easy task, especially when dealing with extreme

439 responses, as it involves the simulation of several stochastic realizations for each

440 environmental condition. This implies the use of large computational resources, which

441 are not often accessible. So a mandatory step in this line of research is to find a trade-

442 off between the accuracy of the results and minimizing the computational cost. 


\section{Journal of Offshore Mechanics and Artic Engineering}

The present work has focused on the understanding of uncertainties in a

444 monopile OWT and, it has addressed the study of two issues of particular importance:

445 the simulation length (statistical uncertainty) and the foundation flexibility (model

446 uncertainty). In the initial part of this research, attention was focused on analyzing the

447 influence of the simulation length on the long-term extrapolation process of two types

448 of dynamic responses. From the review of previous research, it was seen that there is no

449 consensus on the minimum time to be considered in the simulations. Also, it was found

450 that in most of the papers, certain aspects had not been taken into account and that

451 could have influenced their conclusions. Among these aspects, which have been covered

452 in the present study, we can mention that:

- Most authors limited their analysis to short-term extreme values extracted from the time series (except [17]). In those cases, it was concluded that the simulation length did not have much influence on the final results. However, in the present work, it was found that simulation length has a more pronounced effect in the long term. preferable for characterizing dynamic responses when a large number of time series is not available, this was not our case. For this reason, it was 
Journal of Offshore Mechanics and Artic Engineering

464

465

466

467

468

469

470

471

472

473

474

475

476

477

478

479

480

481 completely reasonable, since covering all these aspects to perform an analysis and

482 characterization of extreme response involves an important computational effort. In this

483 work, it has been possible to consider all these missing aspects because the MECM

484 made it possible to significantly reduce the number of environmental conditions to be 485

fit of the method was assessed through a hypothesis test, which gave good results.

- In the papers where only short-term maximum responses were considered, the authors chose to compare singular values of the different stochastic realizations or to average them, rather than characterize them by statistical fitting. In contrast, in the work developed in this paper, the extreme values were fitted to a statistical extreme value distribution (Gumbel), which allowed determining the most probable extreme loads to be used as a more advanced and accurate comparison metric.

- It was observed that joint probability distributions of the environmental variables were considered only in some studies. This could have led to analyzing environmental conditions that did not correspond to a target return period. In the present investigation, the joint probability distribution of a specific site has been taken into account and, this is a mandatory requirement to use the MECM and apply the 50-year extrapolation.

Although there were certain gaps in the previous investigations, this is evaluated. 


\section{Journal of Offshore Mechanics and Artic Engineering}

The main finding of the initial part of this work has been to determine

487 quantitatively that the simulation length of 10 -min is not sufficient to achieve low levels

488 of uncertainty in the long-term extrapolation (50 years), as is widely believed. In the

489 short term, this aspect does not have much influence (one hour). It was also observed

490 that good results are obtained with at least 30-min of simulation for the FASF. For

491 FABM, there is a significant deviation for a duration of 10-min, which is reduced when

492 considering 20 or 30-min, although the level of deviation is still appreciable.

In the final part of this work, the effects of a flexible foundation on two dynamic

494 responses have been evaluated. The behavior of these responses has been addressed in

495 the short and long term. The IAF foundation model was used to account for this

496 flexibility. This approach solves the shortcomings of the traditional AF model and, at the

497 same time, offers a good trade-off between enhanced reproduction of soil conditions

498 and the computational effort required to run several stochastic simulations.

500 taken into account in the analysis. These gaps were addressed in the present research as 501 follows:

- For the present study, attention was focused on two dynamic responses of particular relevance for monopile design, the FASF, and the FABM. In previous literature, only the FABM was analyzed. since shorter simulations produce significant deviations when applying 
Journal of Offshore Mechanics and Artic Engineering

extrapolation, especially for FABM. In previous research, 10-minute simulations were used.

- In the analysis developed, extreme values were adjusted to a probability function to obtain the most probable extreme value in the short term. This function was used to obtain long-term values by extrapolation, which revealed the influence of the foundation flexibility in the location of the critical wind speed. In contrast to earlier work, where the technique of averaging singular maximum short-term values was used. the wind turbine has been evaluated. This allowed determining the trends of extreme responses, as well as points where there is a change in the critical wind speed when considering a rigid and flexible foundation. In a previous analysis, only two wind speeds had been evaluated, an insufficient number to capture these inflection points.

522 the model leads to a shift of the critical wind speed, as well as an increase in the value of

523 the extrapolated response for the FABM. This wind speed is very important since it

524 allows restricting the short-term conditions to be considered when more accurate 525 techniques are required to find the value of the long-term extreme response, e.g. the 526 simplified long-term analysis (SLTA). An additional finding is that FASF and FABM are

527 found to be weakly sensitive to the inclusion of foundation flexibility in the short term, 528 and the FASF is also almost insensitive in the long term. 
Journal of Offshore Mechanics and Artic Engineering

The results obtained in the present research are intended to serve as a basis for

530 orienting efforts related to structural optimization, establishing guiding parameters on

531 which aspects are crucial and which are irrelevant for the control of uncertainty

532 propagation in reliability-based designs. In that sense, it contributes to the main

533 objective of reducing the LCOE of offshore wind energy.

$534 \quad$ Future research should consider the effects of uncertainties related to wind

535 turbulence level and turbulence models. In addition, the inclusion of higher-order wave

536 kinematics and advanced wave load models should be evaluated since their influence is

537 greater in cases of shallow water. Also, the effect of phenomena such as ringing and

538 springing should be considered, as they can influence the value of extreme response

539 values. Finally, future research should address the effect of uncertainties on the

540 behavior of larger turbines.

541

542

543

544

545 team at Queen's University Belfast for their support for this work regarding

546 infrastructure and training in the use of HPC resources.

\section{FUNDING}

548 The first author wants to thank the "Consejo Nacional de Ciencia y Tecnología"

549 (CONCYTEC) and the "Fondo Nacional de Desarrollo Científico, Tecnológico y de

550 Innovación Tecnológica" (FONDECYT) for their financial support to this work, contract

551 reference number 174/2019. 
Journal of Offshore Mechanics and Artic Engineering

553

554

555

556

557

558

559

560

561

562

563

564

565

566

567

568

569

570

571

572

573

574

575

576

577

578

579

580

581

582

583

584

585

586

587

\section{REFERENCES}

[1] REN21, 'RENEWABLES 2019: GLOBAL STATUS REPORT', 2019. Accessed: Jun. 24, 2020. [Online]. Available: https://www.ren21.net/gsr-2019/.

[2] C. Ng and L. Ran, Offshore Wind Farms: Technologies, Design and Operation, 1st ed. Woodhead Publishing, 2016.

[3] Siemens Gamesa Renewable Energy, 'Powered by change: Siemens Gamesa launches $14 \mathrm{MW}$ offshore Direct Drive turbine with 222-meter rotor'. https://www.siemensgamesa.com/en-int/newsroom/2020/05/200519-siemensgamesa-turbine-14-222-dd (accessed Jun. 24, 2020).

[4] International Energy Agency, 'Offshore Wind Outlook 2019: World Energy Outlook Special Report', 2019. Accessed: Jun. 24, 2020. [Online]. Available: https://www.iea.org/reports/offshore-wind-outlook-2019.

[5] X. Wang, X. Zeng, J. Li, X. Yang, and H. Wang, 'A review on recent advancements of substructures for offshore wind turbines', Energy Convers. Manag., vol. 158, pp. 103-119, 2018, doi: 10.1016/j.enconman.2017.12.061.

[6] R. R. Damiani, 'Uncertainty and Risk Assessment in the Design Process for Wind', 2018. doi: 10.2172/1421379.

[7] J. Fogle, P. Agarwal, and L. Manuel, 'Towards an improved understanding of statistical extrapolation for wind turbine extreme loads', Wind Energy, vol. 11, pp. 613-635, 2008, doi: 10.1002/we.303.

[8] P. Thoft-Christensen and M. J. Baker, Structural Reliability Theory and Its Applications. Springer, 1982.

[9] Z. Jiang, W. Hu, W. Dong, Z. Gao, and Z. Ren, 'Structural reliability analysis of wind turbines: A review', Energies, vol. 10, no. 12, p. 2099, 2017, doi: 10.3390/en10122099.

[10] X. Chen, Z. Jiang, Q. Li, Y. Li, and N. Ren, 'Extended Environmental Contour Methods for Long-Term Extreme Response Analysis of Offshore Wind Turbines', J. Offshore Mech. Arct. Eng., vol. 142, no. 5, 2020, doi: 10.1115/1.4046772.

[11] P. Agarwal and L. Manuel, 'Simulation of offshore wind turbine response for longterm extreme load prediction', Eng. Struct., vol. 31, no. 10, pp. 2236-2246, 2009, doi: 10.1016/j.engstruct.2009.04.002.

[12] I. B. Løken and A. M. Kaynia, 'Effect of foundation type and modelling on dynamic response and fatigue of offshore wind turbines', Wind Energy, vol. 22, no. 12, pp. 1667-1683, 2019, doi: 10.1002/we.2394. 
Journal of Offshore Mechanics and Artic Engineering

588

589

590

591

592

593

594

595

596

597

598

599

600

601

602

603

604

605

606

607

608

609

610

611

612

613

614

615

616

617

618

619

620

621

622

623

[13] E. A. Rendon and L. Manuel, 'Long-term loads for a monopile-supported offshore wind turbine', Wind Energy, vol. 17, no. 2, pp. 209-223, 2014, doi: 10.1002/we.1569.

[14] G. Stewart, M. Lackner, L. Haid, D. Matha, J. Jonkman, and A. Robertson, 'Assessing fatigue and ultimate load uncertainty in floating offshore wind turbines due to varying simulation length', 11th Int. Conf. Struct. Saf. Reliab., pp. 239-246, 2013, doi: 10.1201/b16387.

[15] M. I. Kvittem and T. Moan, 'Time domain analysis procedures for fatigue assessment of a semi-submersible wind turbine', Mar. Struct., vol. 40, pp. 38-59, 2015, doi: 10.1016/j.marstruc.2014.10.009.

[16] L. Haid, G. Stewart, J. Jonkman, A. Robertson, M. Lackner, and D. Matha, 'Simulation-length requirements in the loads analysis of offshore floating wind turbines', Proc. Int. Conf. Offshore Mech. Arct. Eng. OMAE, 2013, doi: 10.1115/OMAE2013-11397.

[17] D. Zwick and M. Muskulus, 'The simulation error caused by input loading variability in offshore wind turbine structural analysis', Wind Energy, vol. 18, no. 8, pp. 1421-1432, 2015, doi: 10.1002/we.1767.

[18] C. Hübler, C. G. Gebhardt, and R. Rolfes, 'Development of a comprehensive database of scattering environmental conditions and simulation constraints for offshore wind turbines', Wind Energy Sci., vol. 2, no. 2, pp. 491-505, 2017, doi: 10.5194/wes-2-491-2017.

[19] A. C. Pillai, P. R. Thies, and L. Johanning, 'Impact of Simulation Duration for Offshore Floating Wind Turbine Analysis Using a Coupled FAST-OrcaFlex Model', Proc. Int. Conf. Offshore Mech. Arct. Eng. OMAE, 2019, doi: 10.1115/omae201995159.

[20] E. Bush, P. Agarwal, and L. Manuel, 'The influence of foundation modeling assumptions on long-term load prediction for offshore wind turbines', in International Conference on Offshore Mechanics and Arctic Engineering, 2008, vol. 48234, pp. 819-824, doi: 10.1115/OMAE2008-57893.

[21] E. Bush and L. Manuel, 'The influence of foundation modeling assumptions on long-term load prediction for offshore wind turbines', in International Conference on Offshore Mechanics and Arctic Engineering, 2009, vol. 43444, pp. 1075-1083, doi: 10.1115/OMAE2009-80050.

[22] S. Haver and S. R. Winterstein, 'Environmental contour lines: A method for estimating long term extremes by a short term analysis', Trans. - Soc. Nav. Archit. Mar. Eng., 2008, [Online]. Available: 
Journal of Offshore Mechanics and Artic Engineering

624

625

626

627

628

629

630

631

632

633

634

635

636

637

638

639

640

641

642

643

644

645

646

647

648

649

650

651

652

653

654

655

656

657

658

https://www.researchgate.net/profile/Steven_Winterstein/publication/2423158 33_Environmental_Contour_Lines_A_Method_for_Estimating_Long_Term_Extre mes_by_a_Short_Term_Analysis/links/5e84b9144585150839b33618/Environme ntal-Contour-Lines-A-Method-for-Estimatin.

[23] M. Rosenblatt, 'Remarks on a multivariate transformation', Ann. Math. Stat., vol. 23, no. 3, pp. 470-472, 1952, doi: 10.1214/aoms/1177729394.

[24] S. R. Winterstein, T. C. Ude, C. A. Cornell, P. Bjerager, and S. Haver, 'Environmental Parameters for Extreme Response: Inverse Form with Omission Factors', Proc. Int. Conf. Struct. Saf. Reliab., 1993, [Online]. Available: https://www.researchgate.net/publication/288935223_Environmental_paramete rs_for_extreme_response_inverse_FORM_with_omission_factors.

[25] Q. Li, Z. Gao, and T. Moan, 'Modified environmental contour method for predicting long-term extreme responses of bottom-fixed offshore wind turbines', Mar. Struct., vol. 48, pp. 15-32, 2016, doi: 10.1016/j.marstruc.2016.03.003.

[26] T. Burton, N. Jenkins, D. Sharpe, and E. Bossanyi, 'Design loads for horizontal axis wind turbines', in Wind energy handbook, 2nd ed., John Wiley \& Sons, 2011, pp. 296-302.

[27] WAFO Group, 'WAFO - A Matlab Toolbox for Analysis of Random Waves and Loads - A Tutorial', Sweden, 2000. Accessed: Jun. 24, 2020. [Online]. Available: http://www.maths.Ith.se/matstat/wafo.

[28] J. Jonkman, S. Butterfield, W. Musial, and G. Scott, 'Definition of a 5-MW reference wind turbine for offshore system development', OSTI, 2009. doi: $10.2172 / 947422$.

[29] L. Li, Z. Gao, and T. Moan, 'Joint Environmental Data at Five European Offshore Sites for Design of Combined Wind and Wave Energy Devices', Proc. Int. Conf. Offshore Mech. Arct. Eng. OMAE, 2013, doi: 10.1115/omae2013-10156.

[30] B. J. Jonkman, 'Turbsim User's Guide: Version 1.50', 2009. doi: 10.2172/965520.

[31] International Electrotechnical Commission, 'IEC 61400-1:2005. Wind turbines Part 1: Design requirements'. International Electrotechnical Commission, 2005, Accessed: Jun. 24, 2020. [Online]. Available: https://webstore.iec.ch/publication/5426.

[32] J. M. Jonkman and M. L. Buhl Jr, 'FAST User's Guide - Updated August 2005', 2005. doi: 10.2172/15020796.

[33] J. Jonkman, A. Robertson, and G. Hayman, 'HydroDyn User's Guide and Theory Manual (draft version)', 2014. 
Journal of Offshore Mechanics and Artic Engineering

659 [34] M. Karimirad, Offshore Energy Structures: For Wind Power, Wave Energy and 660 Hybrid Marine Platforms, vol. 1. Springer, 2014.

661

662

[35] D. Barreto, A. Moghtadaei, M. Karimirad, and A. Ortega, 'Sensitivity Analysis of a

663

664 Bottom Fixed Offshore Wind Turbine Using the Environmental Contour Method', Proc. Int. Conf. Offshore Mech. Arct. Eng. OMAE, 2019, doi: 10.1115/OMAE201995390.

665

[36] E. E. Bachynski, T. Kristiansen, and M. Thys, 'Experimental and numerical investigations of monopile ringing in irregular finite-depth water waves', Appl.

667 Ocean Res., vol. 68, pp. 154-170, 2017, doi: 10.1016/j.apor.2017.08.011.

668

669 
Journal of Offshore Mechanics and Artic Engineering

670

671

\section{Figure Captions List}

Fig. 1 Diagram of the fictitious beams considered in the IAF method, adapted from [12].

Fig. 2 Most probable value from 10-min (red circles), 20-min (blue squares), 30min (green triangles) simulations extrapolated to a 1-hr level, and most probable value from 1-hr (black diamonds) simulations versus mean wind speed for FASF.

Fig. 3 Most probable value from 10-min (red circles), 20-min (blue squares), 30min (green triangles) simulations extrapolated to a 1-hr level, and most probable value from 1-hr (black diamonds) simulations versus mean wind speed for FABM.

Fig. $4 \quad$ Relative errors of the most probable values extrapolated to a 1-hr level with respect to most probable values from 1-hr simulations for the FASF.

Fig. 5 Relative errors of the most probable values extrapolated to a 1-hr level with respect to most probable values from 1-hr simulations for the FABM.

Fig. 6 Most probable value from 10-min (red circles), 20-min (blue squares), 30min (green triangles), and 1-hr (black diamonds) extrapolated to a 50-yr level from simulations versus mean wind speed for FASF.

Fig. 7 Most probable value from 10-min (red circles), 20-min (blue squares), 30min (green triangles), and 1-hr (black diamonds) extrapolated to a 50-yr 
Journal of Offshore Mechanics and Artic Engineering

level from simulations versus mean wind speed for FABM.

Relative errors of the most probable values extrapolated to 50 -yr level

Fig. 8 with respect to most probable values extrapolated from 1-hr simulations for the FASF.

Fig. 9 Relative errors of the most probable values extrapolated to 50-yr level with respect to most probable values extrapolated from 1-hr simulations for the FABM.

Fig. 10 Most probable value of extreme response for FASF from 1-hr simulations considering rigid foundation (red circles) and IAF foundation (black diamonds) versus mean wind speed.

Fig. 11 Most probable value of extreme response for FABM from 1-hr simulations considering rigid foundation (red circles) and IAF foundation (black diamonds) versus mean wind speed.

Fig. 12 Relative error of 1-hr extreme response for FASF (Red) and FABM (black) when a flexible soil model is considered.

Fig. 13 Most probable value of extreme response for FASF extrapolated to 50-yr level considering rigid foundation (red circles) and IAF foundation (black diamonds) versus mean wind speed.

Fig. 14 Most probable value of extreme response for FABM extrapolated to 50yr level considering rigid foundation (red circles) and IAF foundation (black diamonds) versus mean wind speed. 
Journal of Offshore Mechanics and Artic Engineering

Fig. 15 Relative error of extreme response extrapolated to 50-yr level for FASF

(Red) and FABM (black) when a flexible soil model is considered.

672

673 
Journal of Offshore Mechanics and Artic Engineering

674

675

Table $1 \quad$ Number of cases of Gumbel parameter estimation grouped by the range of $p$-values.

Table 2 Environmental conditions considered for the calculation of extreme responses, including 50-yr environmental conditions at "Site 15" [29].

Table 3 Properties of the two fictitious beams employed in the IAF model [12].

676

677 
Journal of Offshore Mechanics and Artic Engineering

678

679

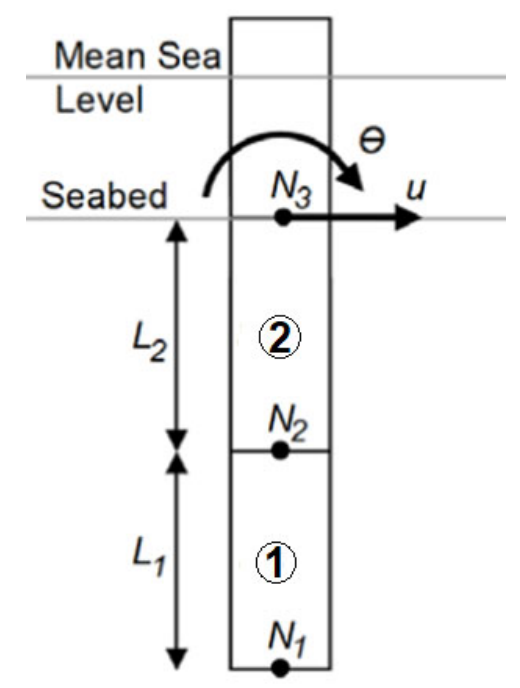

680 
Journal of Offshore Mechanics and Artic Engineering

681

Most probable 1-hr extreme

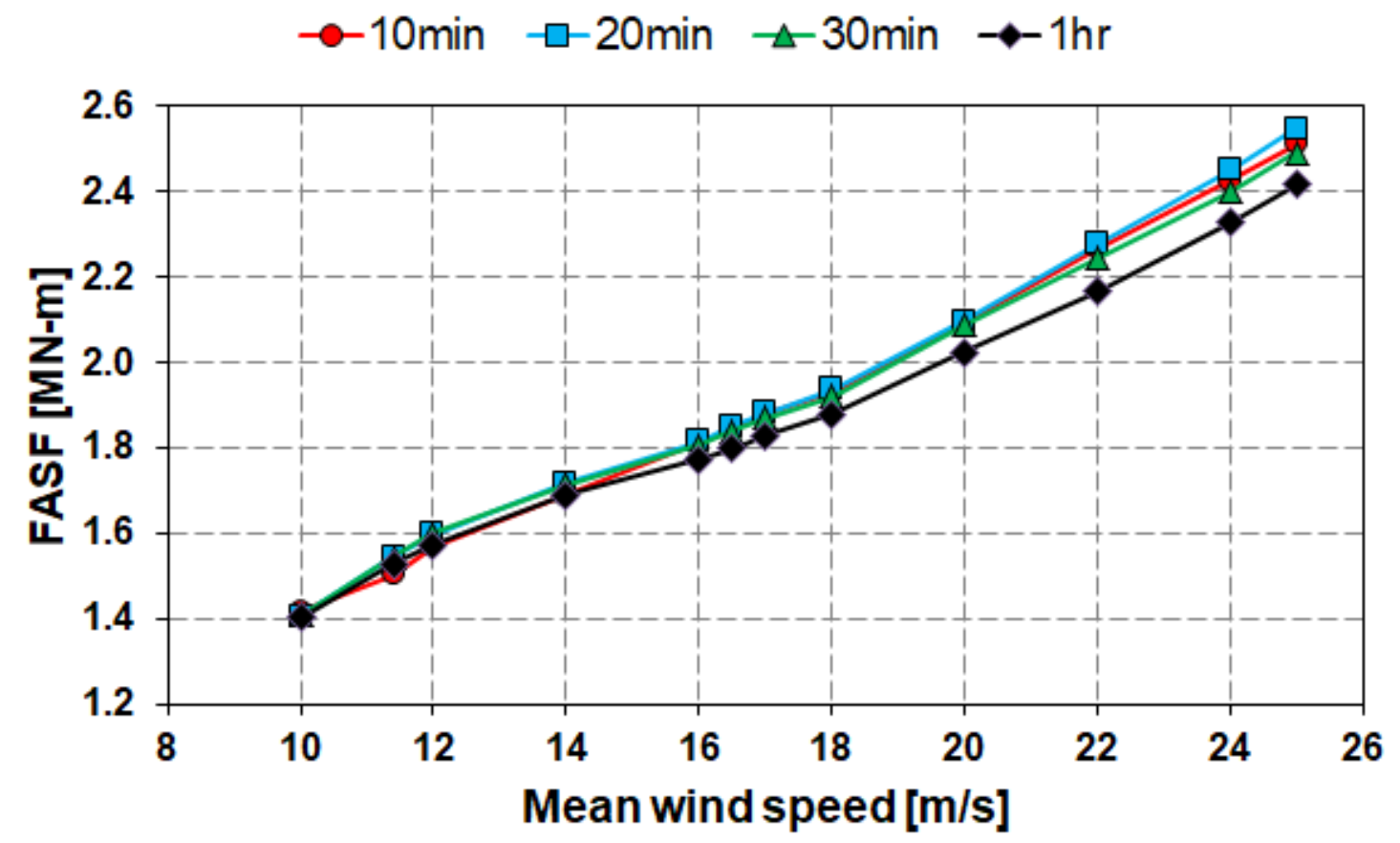

683

684

685 
Journal of Offshore Mechanics and Artic Engineering

686

Most probable 1-hr extreme

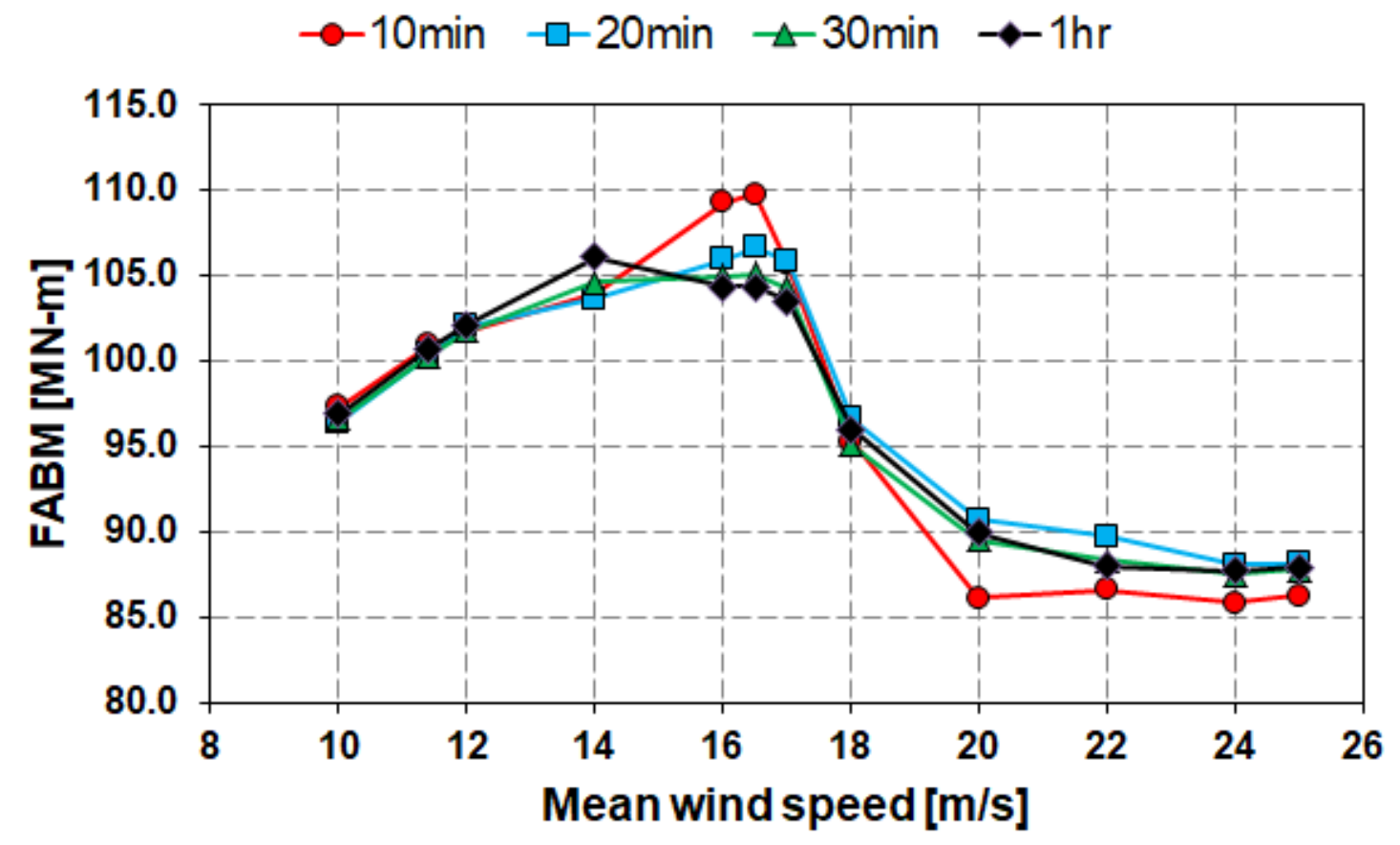

687

688

689 
Journal of Offshore Mechanics and Artic Engineering

690

\section{Most probable 1-hr extreme}

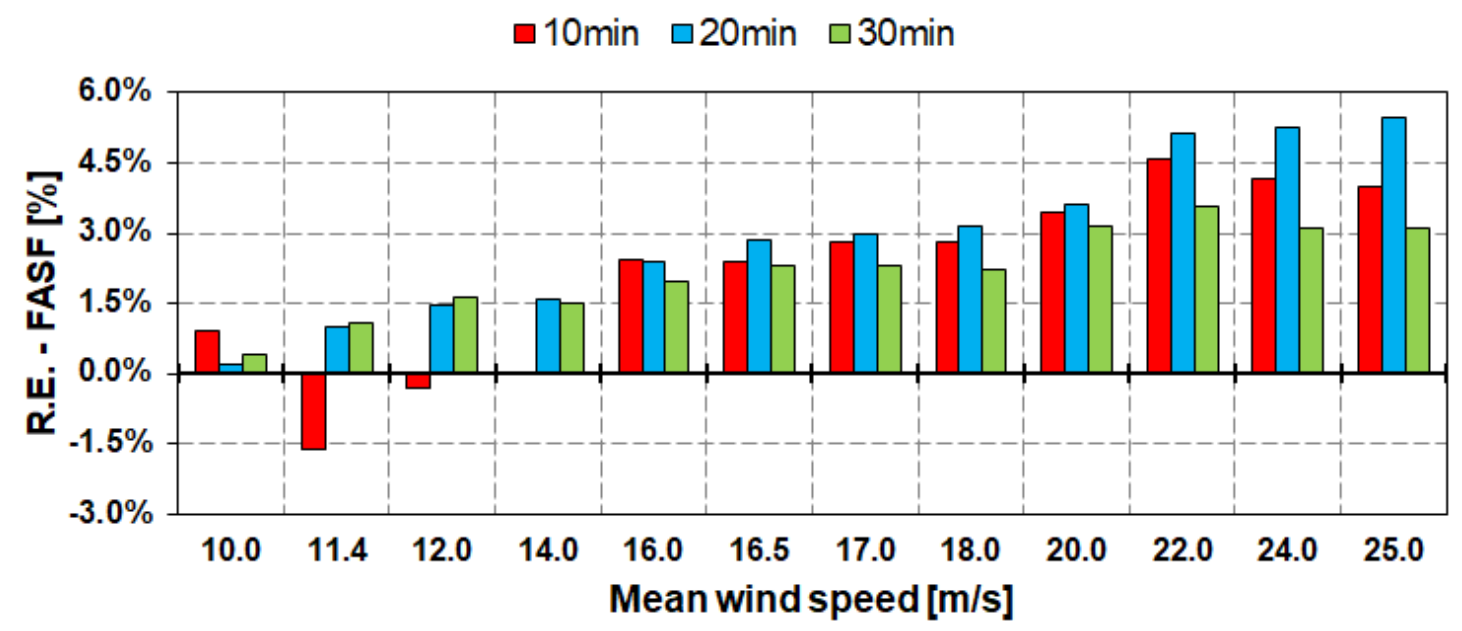

691

692 
Journal of Offshore Mechanics and Artic Engineering

693

\section{Most probable 1-hr extreme}

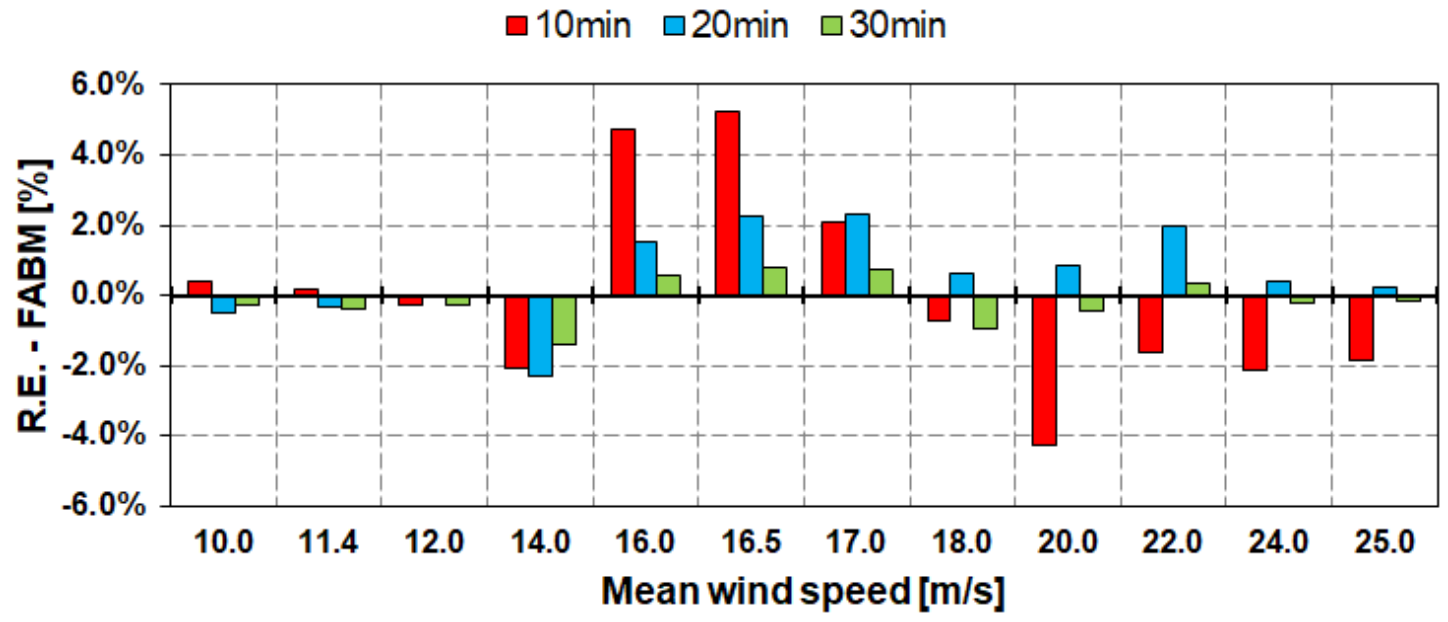

694

695

696 


\section{Most probable 50-yr extreme}

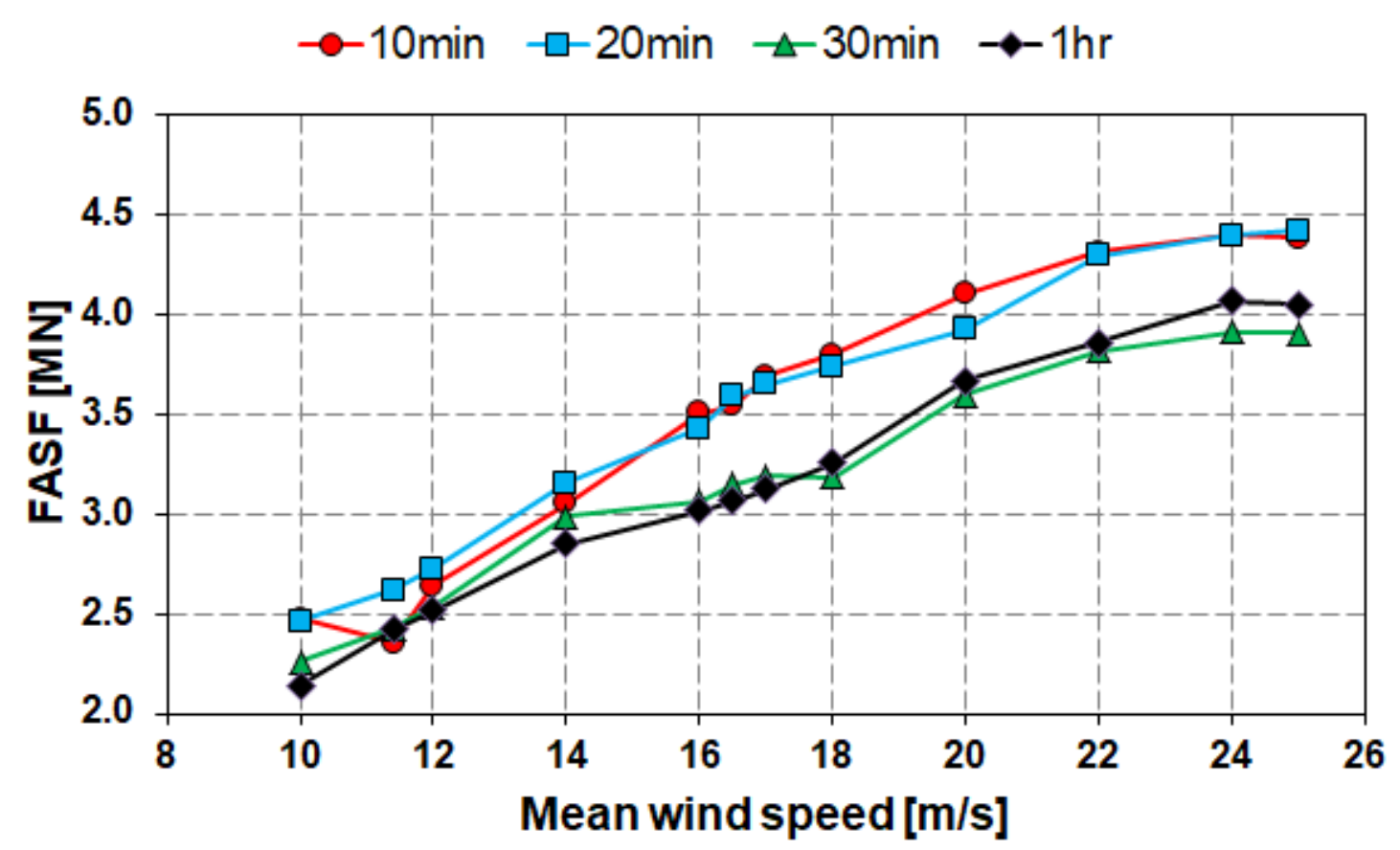

698

699 


\section{Most probable 50-yr extreme}

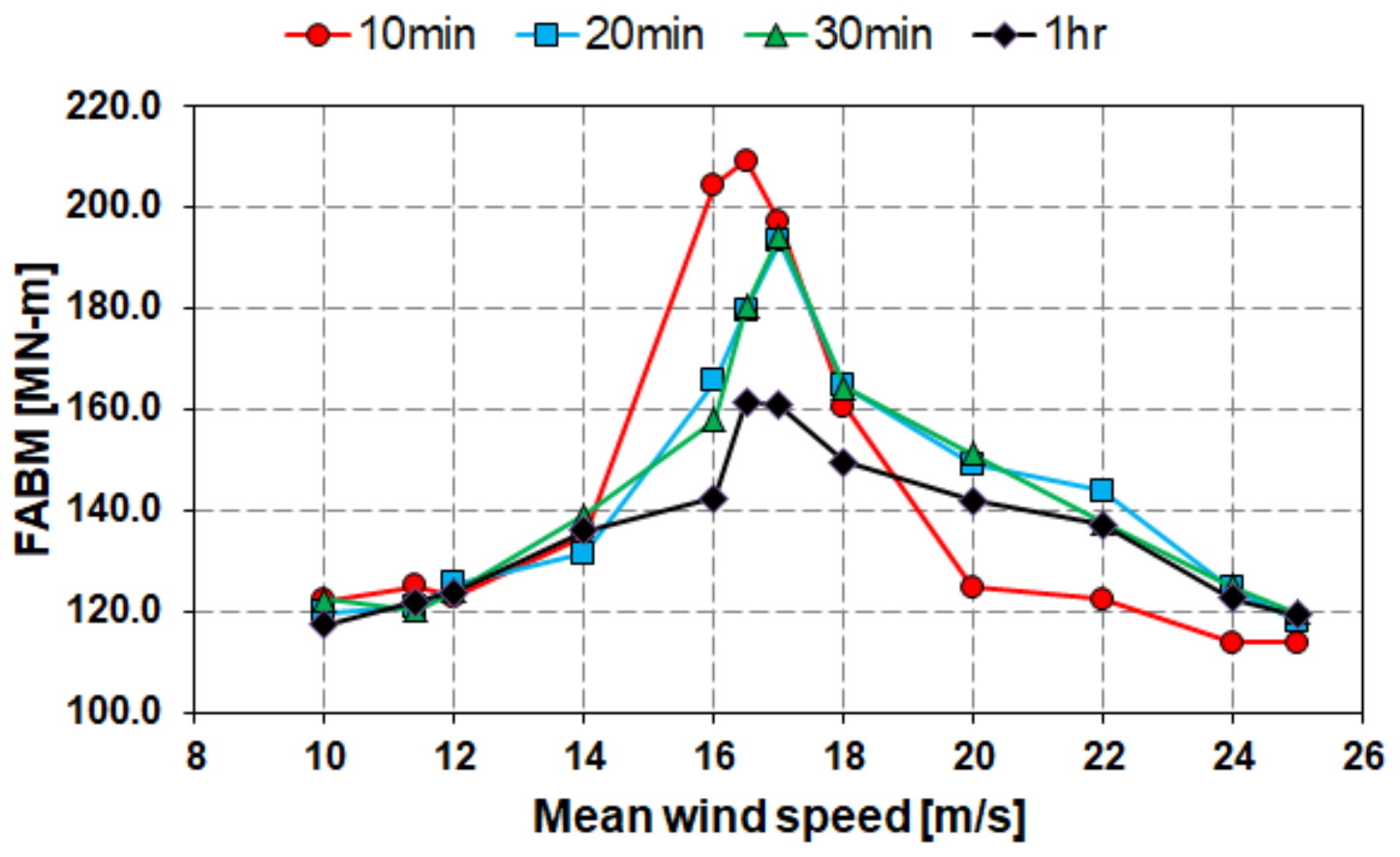

701

702 
Journal of Offshore Mechanics and Artic Engineering

703

\section{Most probable 50-yr extreme}

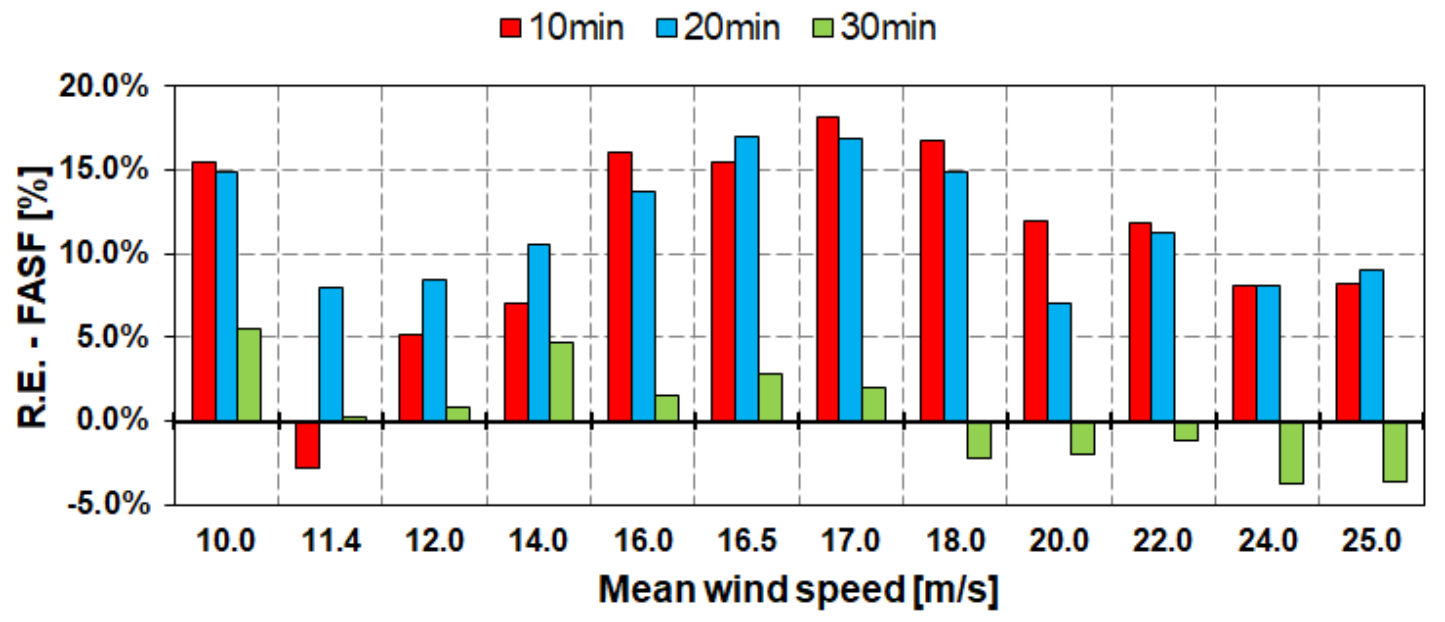


Journal of Offshore Mechanics and Artic Engineering

706

\section{Most probable 50-yr extreme}

$\square 10$ min $\square 20$ min $\square 30$ min

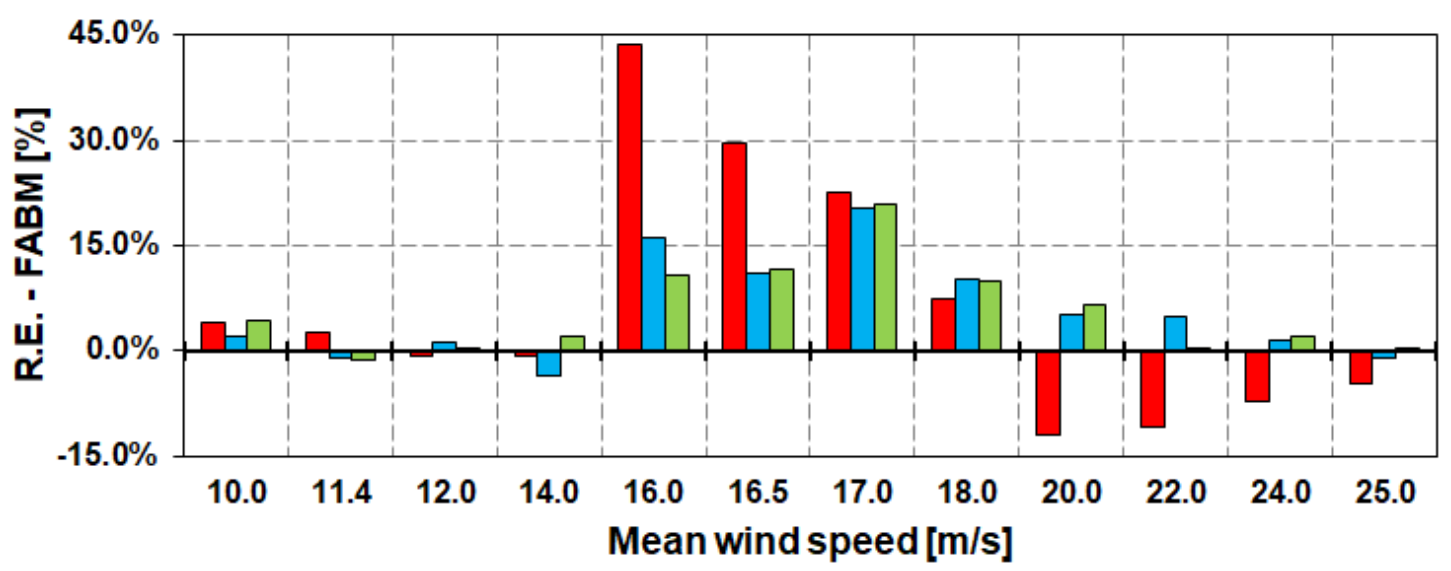

708 
Journal of Offshore Mechanics and Artic Engineering

709

Most probable 1-hr extreme

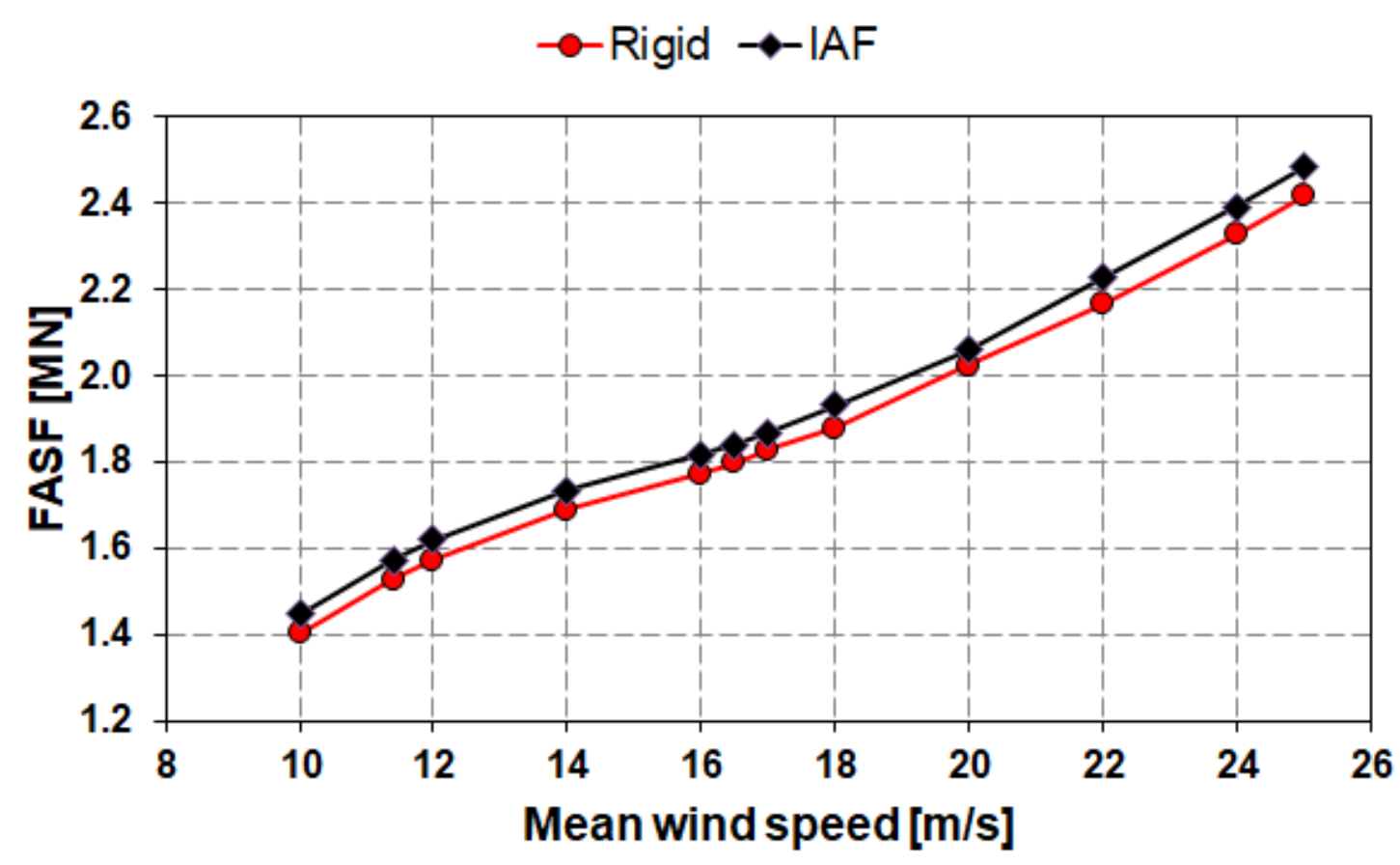

710

711 
Most probable 1-hr extreme

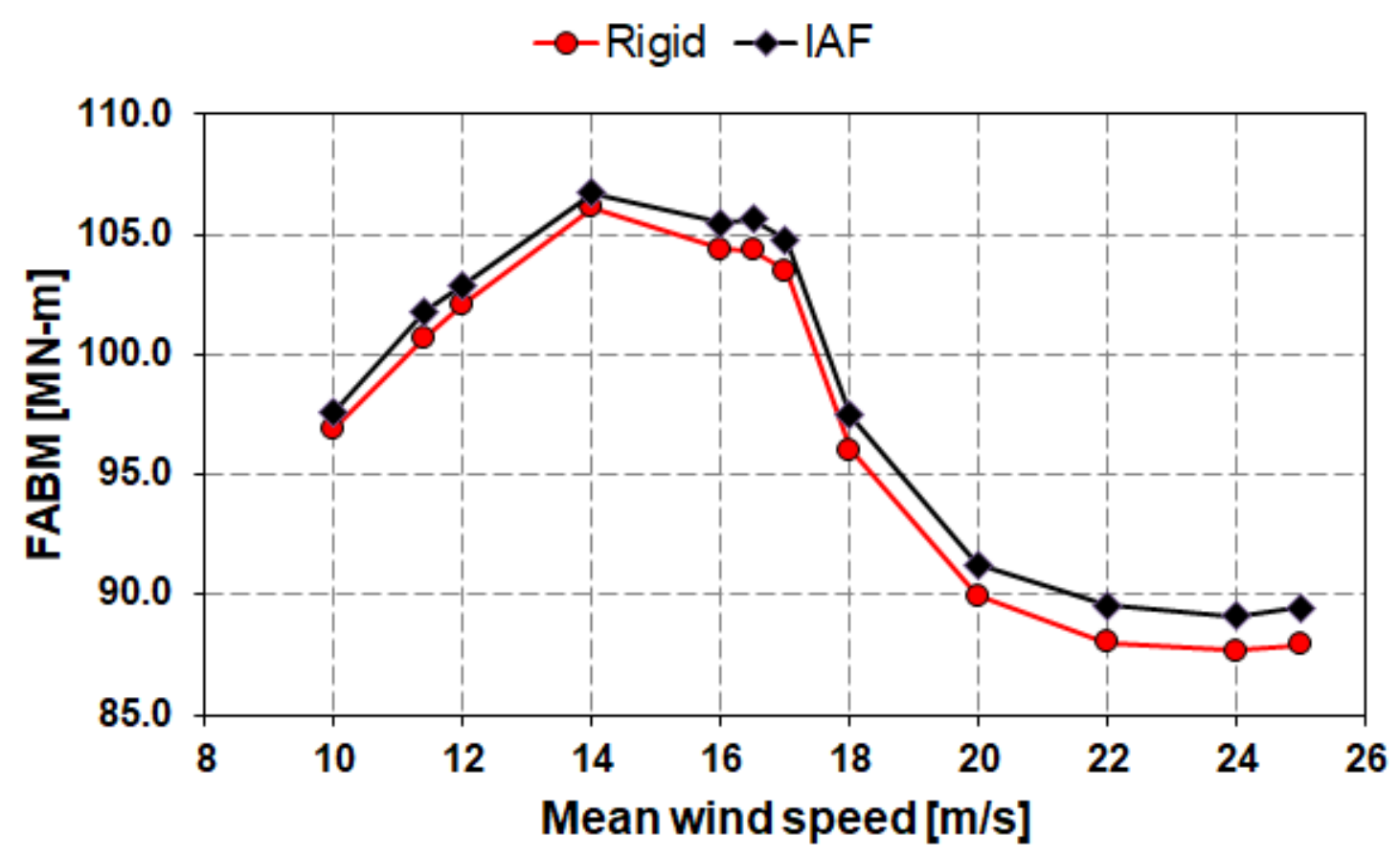

713

714 
Journal of Offshore Mechanics and Artic Engineering

715

Most probable 1-hr extreme

$\square$ FASF $\square$ FABM

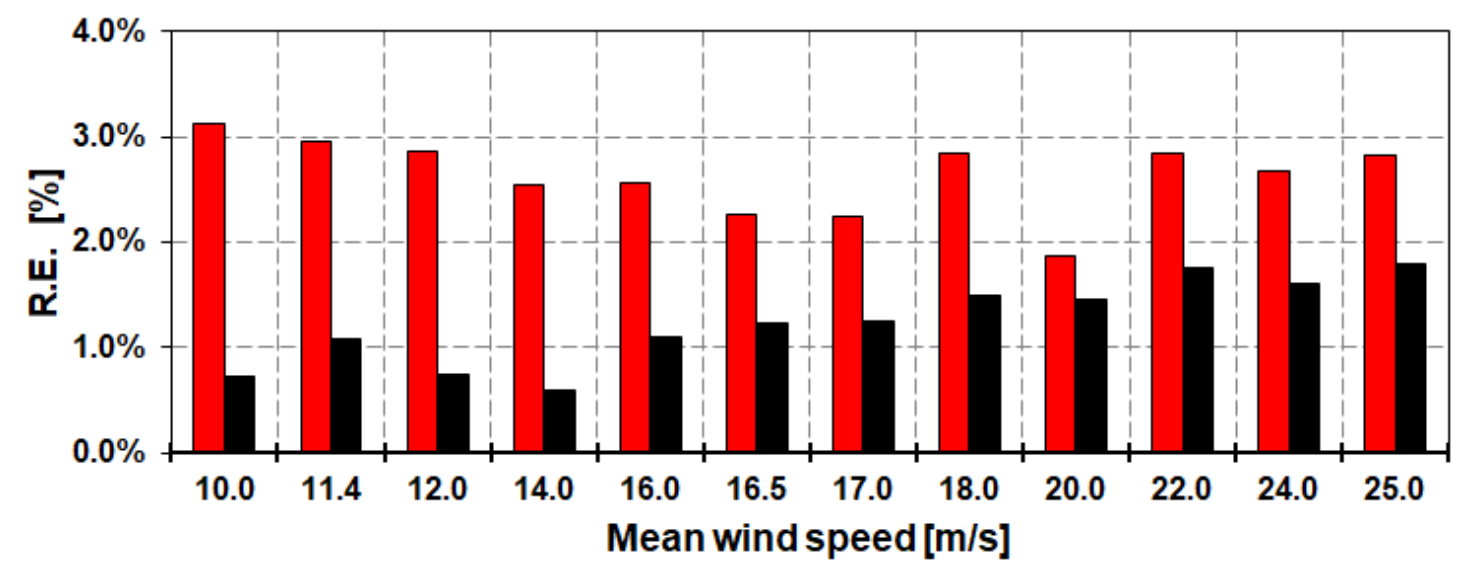

716

717 


\section{Most probable 50-yr extreme}

$\rightarrow-$ Rigid $\rightarrow-$ IAF

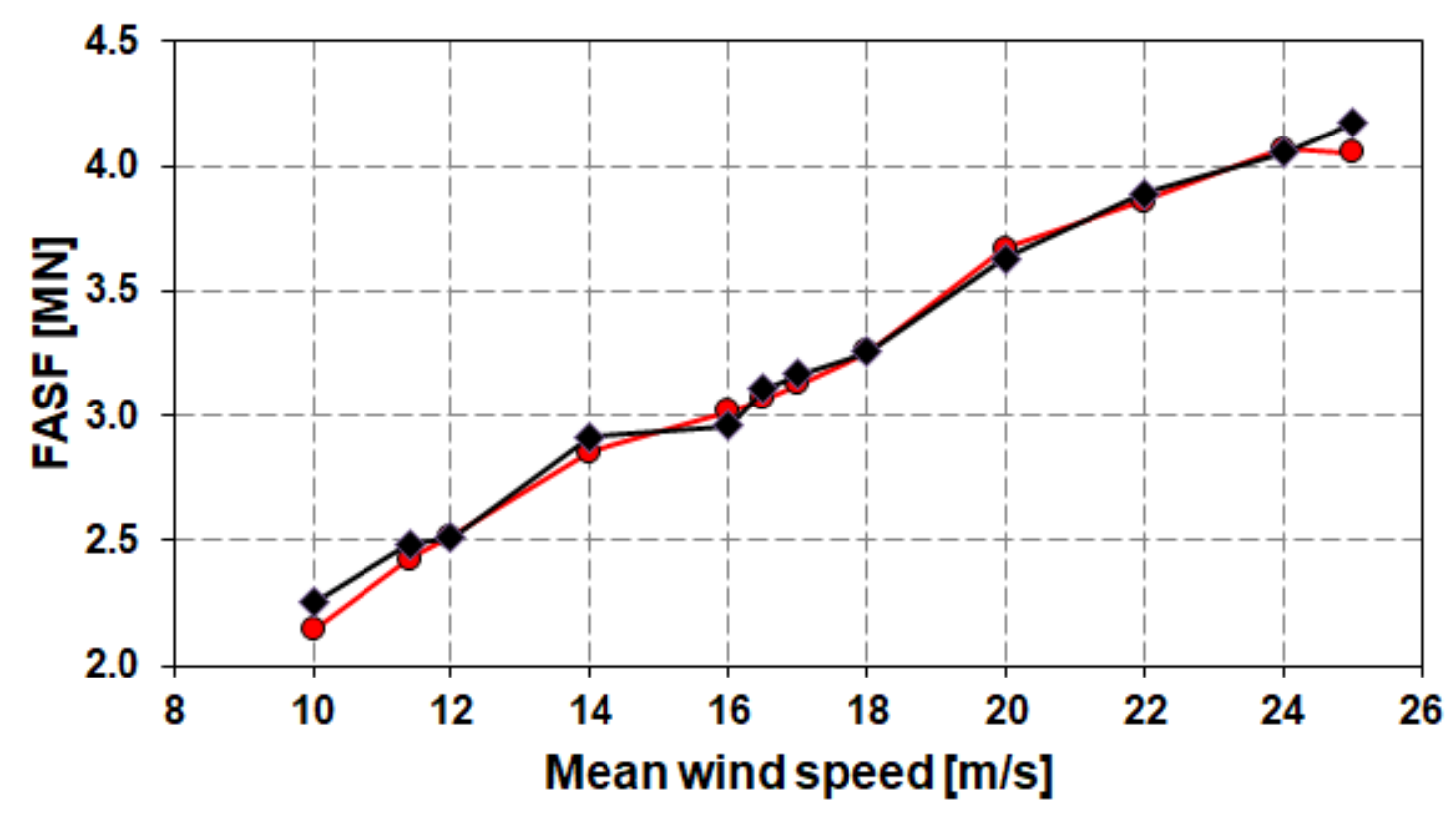

720 
721

\section{Most probable 50-yr extreme}

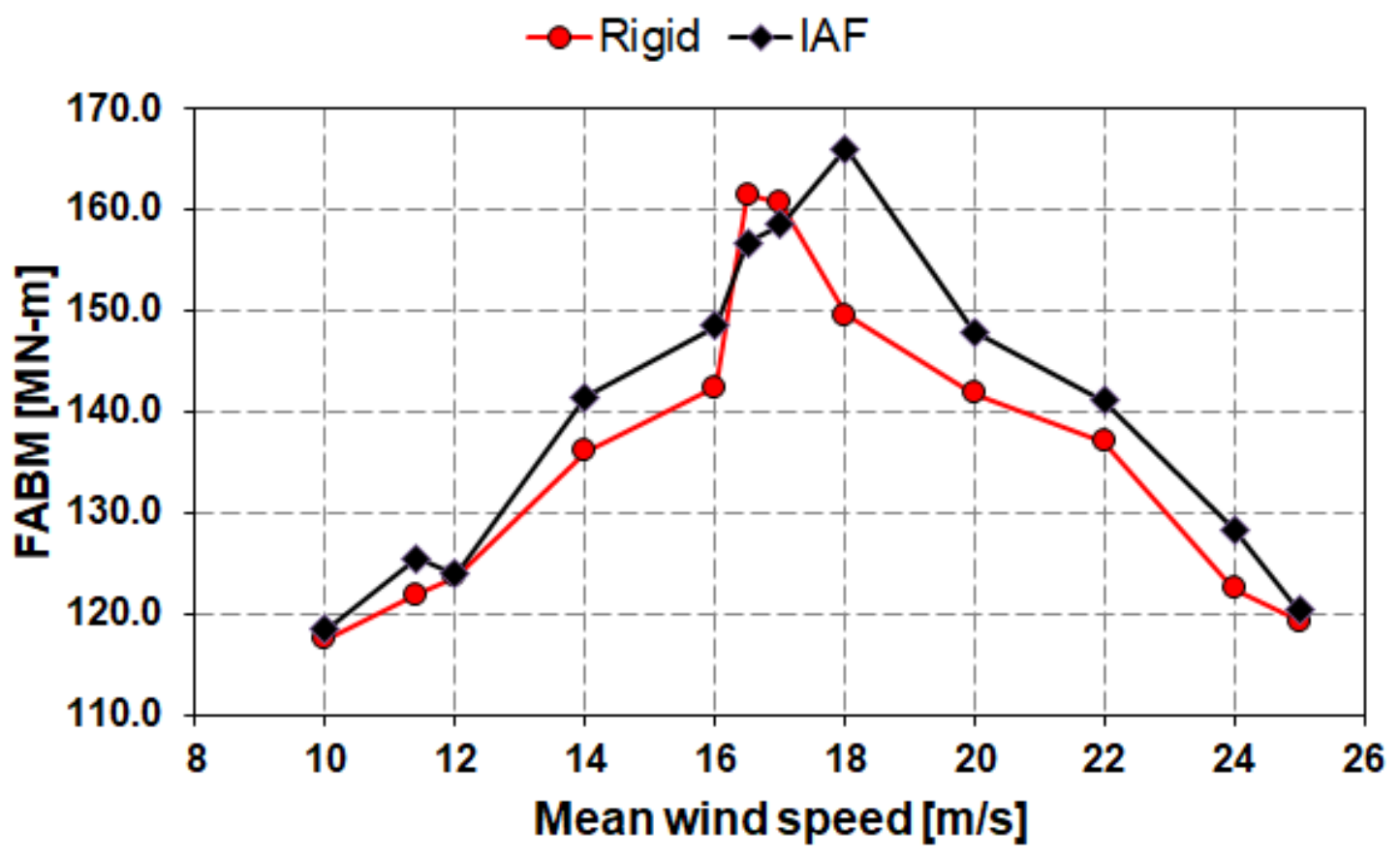

723 
Journal of Offshore Mechanics and Artic Engineering

724

\section{Most probable 50-yr extreme}

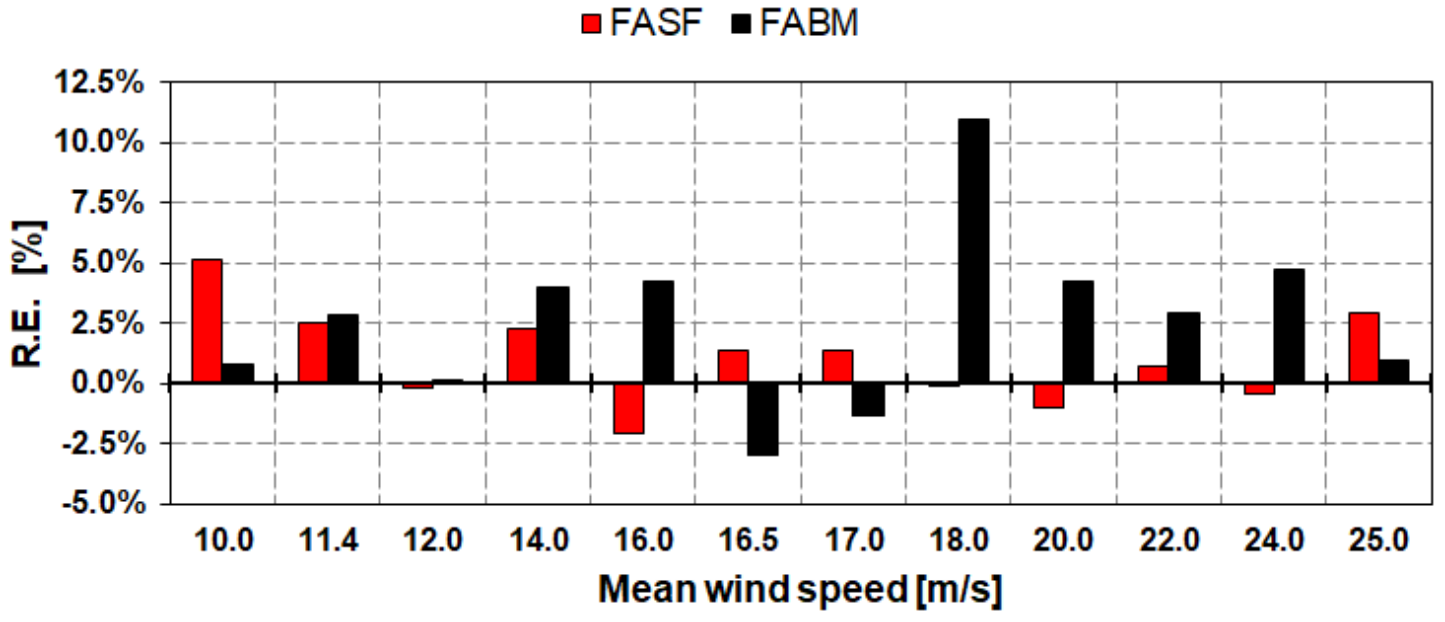


Journal of Offshore Mechanics and Artic Engineering

728

\begin{tabular}{c|c}
\hline $\begin{array}{c}\text { Range of } \\
\text { p-value }\end{array}$ & $\begin{array}{c}\text { Quantity of } \\
\text { cases }\end{array}$ \\
\hline $0.05-0.10$ & 18 \\
\hline $0.10-0.60$ & 68 \\
\hline $0.60-0.99$ & 34 \\
\hline
\end{tabular}

729

730 
Journal of Offshore Mechanics and Artic Engineering

731

\begin{tabular}{c|c|c|c}
\hline $\begin{array}{c}\text { Environmental } \\
\text { Condition }\end{array}$ & $\begin{array}{c}\mathbf{U w}_{\mathbf{w}} \\
{[\mathbf{m} / \mathbf{s}]}\end{array}$ & $\begin{array}{c}\mathbf{H s} \\
{[\mathbf{m}]}\end{array}$ & $\begin{array}{c}\mathbf{T}_{\mathbf{P}} \\
{[\mathbf{s}]}\end{array}$ \\
\hline 1 & 10.00 & 1.564 & 6.969 \\
\hline 2 & 11.40 & 1.801 & 6.996 \\
\hline 3 & 12.00 & 1.908 & 7.016 \\
\hline 4 & 14.00 & 2.280 & 7.112 \\
\hline 5 & 16.00 & 2.678 & 7.247 \\
\hline 6 & 16.50 & 2.781 & 7.287 \\
\hline 7 & 17.00 & 2.886 & 7.328 \\
\hline 8 & 18.00 & 3.100 & 7.415 \\
\hline 9 & 20.00 & 3.545 & 7.610 \\
\hline 10 & 22.00 & 4.011 & 7.828 \\
\hline 11 & 24.00 & 4.497 & 8.067 \\
\hline 12 & 25.00 & 4.748 & 8.194 \\
\hline
\end{tabular}

$50 \mathrm{yr}$ conditions for site 15 :

$\mathrm{U}_{\mathrm{W}}=27.20 \mathrm{~m} / \mathrm{s} @ 10 \mathrm{~m} \mathrm{H} \mathrm{H}_{\mathrm{S}}=8.66 \mathrm{~m} \mathrm{~T} \mathrm{~T}_{\mathrm{P}}=6.93 \mathrm{~s}$ 
Journal of Offshore Mechanics and Artic Engineering

734

\begin{tabular}{c|c|c|c|c|c}
\hline Beam & $\begin{array}{c}\mathrm{L} \\
{[\mathrm{m}]}\end{array}$ & $\begin{array}{c}\mathrm{D} \\
{[\mathrm{m}]}\end{array}$ & $\begin{array}{c}\text { Thickness } \\
{[\mathrm{m}]}\end{array}$ & $\begin{array}{c}\mathrm{I} \\
{\left[\mathrm{m}^{4}\right]}\end{array}$ & $\begin{array}{c}\mathrm{E} \\
{\left[\mathrm{N} / \mathrm{m}^{2}\right]}\end{array}$ \\
\hline 1 & 19.88 & 6.00 & 0.06 & 5.089 & $1.743 \times 10^{12}$ \\
\hline 2 & 5.00 & 6.00 & 0.06 & 5.089 & $1.388 \times 10^{11}$ \\
\hline
\end{tabular}

735 